\title{
COMPARISON OF SALIVARY PH CHANGES OF YOUNG ADULTS WITH MINERAL AND ALKALINE WATER RINSE AFTER ACIDIC CHALLENGE. A CLINICAL STUDY
}

\author{
Rania Sayed Mosallam* and Mona Shabaan Mohamed**
}

\begin{abstract}
Objective: The present study was conducted to compare the effect of mineral water and alkaline water after an acidic challenge on salivary $\mathrm{pH}$ of adults.

Methods: 30 dental students in the age group of 20-25 years were randomly divided into two groups according to type of water rinse used either mineral or alkaline water. The salivary $\mathrm{pH}$ was measured at baseline, after candy intake and after water rinse. The results obtained were compared for normality using Kolmogorov-Smirnov and Shapiro-Wilk tests and One-way ANOVA followed by Paired sample t-test.
\end{abstract}

Results: A statistically significance difference was found in salivary $\mathrm{pH}$ between baseline, after candy and after water rinsing. Candy significantly lowered salivary $\mathrm{pH}$. Mineral and alkaline water brought $\mathrm{pH}$ back with non-significant difference with baseline values. However, there was no significance difference between mineral and alkaline water.

Conclusion: Rinsing mouth with water after acidic challenge leads to neutralization of salivary $\mathrm{pH}$ thus preventing caries process in young adults.

KEYWORDS: Mineral water, Alkaline water, Salivary pH.

\section{INTRODUCTION}

Dental caries is the most prevalent disease that affect $60-90 \%$ of schoolchildren and wide majority of adults ${ }^{[1]}$. It is a multifactorial infectious disease that depends on a paradigm of factors. According to Key's triad, microflora plays a significant role in development of dental caries along with host and substrate. Dental caries can not only be controlled by dietary habits, but also by adequate oral hygiene measures ${ }^{[2]}$. However, excluding carbohydrates from diet seems far from realistic. Physical state of food plays an important role in its cariogenic potential. Liquid sugars pass fairly quickly in the

* Ass. Prof. Department of Conservative Dentistry, Faculty of Dentistry, Cairo University.

** Lecturer Department of Operative Dentistry, Faculty of Oral and Dental Medicine, Ahram Canadian University. 
oral cavity with limited contact time, while solid sticky sugars get stuck to the teeth surfaces and the longer the bacteria act on sugars ${ }^{[3-5]}$. Modern life style requires short break times, consumption of junk food and snaking between meals. Most people like to eat candy now and then but doing so regularly has negative effects on oral health because the sugars are gradually released during consumption ${ }^{[6]}$.

Among the host defense mechanisms, saliva, modification in clearance rate and salivary $\mathrm{pH}$ plays an important role in caries prevention. Demineralization and remineralization depends on salivary $\mathrm{pH}$ as a more basic $\mathrm{pH}$ of saliva favors remineralization by precipitating of bicarbonate ions ${ }^{[7]}$. The longer the teeth are exposed to low $\mathrm{pH}$ level, the more likely the development of dental caries.

Dental treatments are costly and impose economic burden particularly in low-income countries. Therefore, preventive strategies are estimated as top priority in oral health programs. People tend to imply hygiene measures that require both less time and efforts ${ }^{[8]}$. Brushing and flossing are most commonly practiced in day to day life ${ }^{[9]}$. However, when it is not feasible, some suppose that rinsing mouth with tap water may minimize the risk of caries development and could be considered as logical emergency substitute for brushing teeth. Water rinsing can aid in washing some large food particles with diluting its contents. Normal drinking water typically has a neutral $\mathrm{pH}$ of 7 , while alkaline water generally has a $\mathrm{pH}$ of 8 or 9 . Because of this, some advocates the benefit of alkaline water in neutralizing acids ${ }^{[10,11]}$.

With this purpose, this randomized clinical trial was conducted to compare the efficacy of mineral and alkaline water rinse in improving saliva $\mathrm{pH}$ after candy intake. This study will benefit preventive dentistry as the main goal is to prevent rather than cure. So, the null hypothesis tested was that there was no difference in saliva $\mathrm{pH}$ after mineral and alkaline water rinsing following acidic challenge.

\section{MATERIAL AND METHODS}

\section{Sample selection:}

A parallel randomized control trial was done on total of 30 dental students from Ahram Canadian University, Faculty of Oral and Dental Medicine, who volunteered to collaborate in this study. The protocol was approved by the ethical committee board of the Research Ethics Committee, Faculty of Dentistry, with ethical number (18-9-74). The inclusion criteria were that subjects should be aged between 20-25 years, medically healthy, had whole permeant dentition and not taking any medications interfering with saliva secretion. The participants with the presence of active dental or periodontal diseases, smokers, pregnancy, TMJ disorders and wearing orthodontic appliances were excluded from the study. Before carrying out the study, the purpose and methodology of the study were clarified to each participant and informed consent form was obtained. Finally, 30 students met the eligibility criteria of the study.

\section{Study design:}

The study was a randomized controlled clinical trial with two parallel arms. Based on the sample size calculated randomization was followed. Subjects were randomly allocated into two groups comprising of 15 subject each: group A: holding mineral water and group B: holding alkaline water. All data regarding the tested materials were tabulated in (Table 1).

Both the observer and participant blinding was carried out as the two types of water were maintained confidential by labelling them. The $\mathrm{pH}$ of saliva was evaluated according to time in relation to saliva collection $(\mathrm{T})$ where $\left(\mathrm{T}_{0}\right)$ represents baseline $\mathrm{pH}$, $\left(\mathrm{T}_{1}\right)$ represents after candy intake and $\left(\mathrm{T}_{2}\right)$ after water rinsing. 
TABLE (1): Materials specifications, chemical composition and manufacturer.

\begin{tabular}{|l|l|l|}
\hline Material & Ingredients & Manufacturer \\
\hline Candy (Toffiy) & $\begin{array}{l}\text { sugar, glucose hydrogenated vegetable oil, edible beef gelatin, fruit juice concentrates } \\
\text { (apple, orange, strawberry, cherry, watermelon), pectin, acid regulator citric acid, } \\
\text { flavors (apple, strawberry, cherry, orange, watermelon), emulsifier soya lecithin. } \\
\text { Contains milk, egg, hazelnut }\end{array}$ & Product of Turkey \\
\hline $\begin{array}{l}\text { Mineral water } \\
\text { (DASANI) }\end{array}$ & $\begin{array}{l}\text { Calcium 30.40, Magnesium 8.64, Sodium 16.80, Potassium 2.19, Bicarbonate } \\
136.46, \text { Sulphate 13.40, Chlorides 13, Silicate 9, T.D.S 171.pH=7 cola company }\end{array}$ & Coca \\
\hline $\begin{array}{l}\text { Alkaline water } \\
\text { (FLO water) }\end{array}$ & $\begin{array}{l}\text { Calcium 24, Magnesium 0.54, Sodium 2.6, Potassium 14, Bicarbonate 29, Sulphate } \\
\text { 0.40, Chlorides 45, Silicate 1, T.D.S 108. pH= 7.9 }\end{array}$ & FLO company \\
\hline
\end{tabular}

\section{Saliva sampling}

Samples were collected in the morning between 10-11am under standardized conditions. Baseline resting saliva samples was collected in a test graduated tube and saliva $\mathrm{pH}$ was measured using digital $\mathrm{pH}$ meter (Pen type $\mathrm{pH}$ meter, $\mathrm{pH}-009(1)$, Promoter China) calibrated with buffer of $\mathrm{pH} 4$ and 7 . The readings of the device were checked regularly for its accuracy. The digital reading was allowed to stabilize for a few seconds then $\mathrm{pH}$ was recorded. After this, the acidic challenge was carried out by having participants to chew candy, followed by saliva collection and $\mathrm{pH}$ measurement. Immediately after this, participants were asked to swish and swift $50 \mathrm{ml}$ of tested water for 5 seconds to ensure thorough distribution and then to swallow and the third salivary $\mathrm{pH}$ reading was recorded.

The recording of the data was done by a welltrained recorder who recorded data on a pro form containing details of the selected test material of each study subject. To minimize bias in the data, an independent observer, blinded to the study's aim, recorded all the readings.

\section{Statistical analysis}

The mean and standard deviation values were calculated for each group in each test. Data were explored for normality using Kolmogorov-Smirnov and Shapiro-Wilk tests and showed parametric (normal) distribution. One-way ANOVA followed by Paired sample t-test was used to compare between two groups in related samples. The significance level was set at $\mathrm{P} \leq 0.05$. Statistical analysis was performed with IBM ${ }^{\circledR}$ SPSS ${ }^{\circledR}$ Statistics Version 20 for Windows.

\section{RESULTS}

The data for different attempts basal saliva $\mathrm{pH}$, $\mathrm{pH}$ after candy intake and after rinsing the mouth with water are shown in Table 2, Figure 1. A statistically significant difference was observed in saliva $\mathrm{pH}$ between baseline, after candy and after two brands of water $(p<0.001)$. No statistically significant difference was found between baseline and after water rinsing. The highest mean value was found in baseline followed by after water rinsing while the least mean value was found after candy. There was no statistically significant difference between Mineral and alkaline water (Table 3). 
TABLE (2): The mean, standard deviation (SD) values of two groups.

\begin{tabular}{|c|c|c|c|c|}
\hline \multirow[t]{2}{*}{ Variables } & \multicolumn{2}{|c|}{ Mineral water } & \multicolumn{2}{|c|}{ Alkaline water } \\
\hline & Mean & SD & Mean & SD \\
\hline Before & $7.43^{\mathrm{a}}$ & 0.41 & $7.63^{a}$ & 0.35 \\
\hline After candy & $5.77^{b}$ & 1.08 & $5.85^{\mathrm{b}}$ & 1.24 \\
\hline $\begin{array}{c}\text { After } \\
\text { treatment }\end{array}$ & $7.30^{\mathrm{a}}$ & 0.46 & $7.24^{\mathrm{a}}$ & 0.96 \\
\hline p-value & \multicolumn{2}{|c|}{$<0.001 *$} & \multicolumn{2}{|c|}{$<0.001 *$} \\
\hline
\end{tabular}

Means with different small letters in the same column indicate statistically significance difference.

*; significant $(p<0.05) \quad n s ;$ non-significant $(p>0.05)$

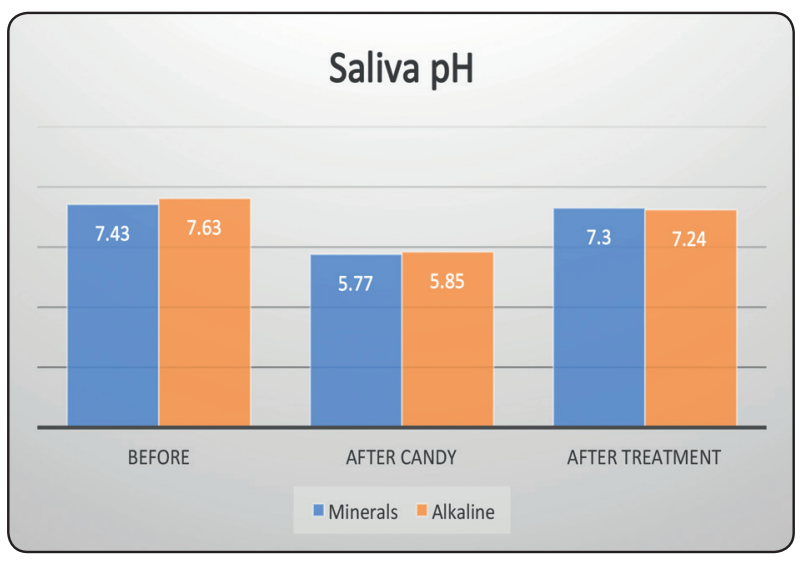

Fig. (1): Bar chart representing changes in salivary $\mathrm{pH}$ of two groups.

TABLE (3): The mean, standard deviation (SD) values of overall results.

\begin{tabular}{|c|c|c|c|c|c|}
\hline \multirow{2}{*}{ Variable } & \multicolumn{2}{|c|}{ Mineral } & \multicolumn{2}{c|}{ Alkaline } & \\
\hline \multirow{2}{*}{ Saliva pH } & Mean & SD & Mean & SD & p-value \\
\cline { 2 - 6 } & $7.30^{\mathrm{a}}$ & 0.46 & $7.24^{\mathrm{a}}$ & 0.96 & $\mathbf{0 . 5 0 5} \mathbf{~ n s}$ \\
\hline
\end{tabular}

Means with different small letters in the same row indicate statistically significance difference. *; significant $(p<0.05)$ ns; non-significant $(p>0.05)$

\section{DISCUSSION}

One of the most essential factors in maintaining healthy dentition is the salivary $\mathrm{pH}$. Rinsing the mouth after meals plays a critical role in maintaining oral health. As previously described, water with $\mathrm{pH}$ at 7.0 proves to be cost-effective preventive measure to prevent dental caries. Modern lifestyle mandates preventive measures that requires less time and efforts. Sticky and solid sugars get stuck to the teeth surface compared to liquid sugars which pass through the oral cavity with limited contact time ${ }^{[12-14]}$. Water was chosen as it is an acceptable, easily available vehicle. Hence, this two-arm randomized controlled clinical trial was undertaken with the aim of assessing the effect of water rinsing on changes in salivary $\mathrm{pH}$ of adult volunteers after candy intake.

In this study, the inclusion criteria included young adults who are at risk for caries development. Also, standardization of age group was done as saliva flow rate tend to change in people younger and older than the selected age ${ }^{[15]}$. In addition, smokers and any subjects under medications were excluded as it might have leveraged saliva flow and composition. Using these criteria, 30 patients were enrolled in the study.

To gain more evidence, saliva $\mathrm{pH}$ was evaluated as it plays important role in regulation remineralization/ demineralization process. The $\mathrm{pH}$ of collected saliva was immediately measured to avoid any time-based changes due to loss of carbon dioxide ${ }^{[16]}$. A digital $\mathrm{pH}$ meter was used as it gives more accurate results than $\mathrm{pH}$ strips besides being portable and faster in measuring the samples.

The null hypothesis was rejected and an obvious finding from this study was that there was a statistically significantly greater rise in saliva $\mathrm{pH}$ after water rinsing with mineral and alkaline water from the $\mathrm{pH}$ after acidic challenge. This finding can seriously challenge the belief that immediate water rinse after intake of sweetened beverages 
and/or food stuffs prevents or at least delays caries development. Candy intake results revealed that there was a significant decrease in salivary $\mathrm{pH}$ as result of extended contact time and adherence to tooth surface ${ }^{[6,11]}$. Rinsing with water thus results in dilution and neutralizing of acidic $\mathrm{pH}$ thus rise in $\mathrm{pH}$ occurs. In addition to the increased clearance rate of food staff which aid to the protective effect of water rinse ${ }^{[17]}$. For intergroup comparison, there was no statistically significant differences between different types of water tested, which could be attributed to a less variation regarding the $\mathrm{pH}$ of mineral and alkaline water leading to insignificant results. Moreover, the presence of bicarbonate ions in the saliva leads to a super saturated solution thereby increasing saliva $\mathrm{pH}$. This finding co-related with the previous study by Dehghan et al. reported that $\mathrm{pH}$ of the saliva increases if the mouth rinse is done with a alkaline $\mathrm{pH}$ solution ${ }^{[18]}$. Panchal and Gurnathan reported that, mineral water composition shows a more alkaline $\mathrm{pH}$ in comparison to tap water which thereby helps in more neutralization of the acid produced thus raising the $\mathrm{pH}$ more as compared to tap water ${ }^{[1]}$. Uma et al also found that, the difference observed in the salivary $\mathrm{pH}$ between the sweetened drinks and mineral water was that the consumption of sweetened drinks led to a drop in salivary $\mathrm{pH}$ while the consumption of mineral water led slight increase in the $\mathrm{pH}$ that was sustained significantly up to $20 \mathrm{~min} .{ }^{[19]}$. This finding was similar to that reported by Azrak et al. An increase in the salivary $\mathrm{pH}$ was attributed to the low buffering capacity of the mineral water and probably to the gustatory stimulus post consumption ${ }^{[20]}$. Kulthanan et al., concluded that $\mathrm{pH}$ of the saliva increases if the mouth rinse is done with a alkaline solution and the composition of mineral water shows a more alkaline $\mathrm{pH}$ compared to tap water which thereby helps in more neutralization of the acid produced thereby raising the $\mathrm{pH}^{[21]}$.

This study suggests that, the use of short-term preventive measures such as water rinsing as an adjunct to mechanical measures can be considered as practical recommendation for caries prevention. However, further studies are necessary to be carried out to assess the impact of rinsing on the molecular level changes of saliva. Also, further studies are recommended to be done on larger samples with wider geographical representations.

\section{CONCLUSION}

Water rinsing can be used as short-term preventive strategies to neutralize salivary $\mathrm{pH}$ after candy intake, which thereby aids as a stop in the process of demineralization thus reducing caries risk in young adult.

\section{ACKNOWLEDGMENT}

The authors would like to thank Dr.Nawal Eidaros and Dr. Doaa Gamal, Ass. Lecturer in Operative Dentistry Department, Faculty of oral and dental medicine, Ahram Canadian University, for assisting in study design, Yasmeen Abo-Elfotoh, Mohamed Hossam (Fifth year student, Ahram Canadian University, Giza, Egypt) for participation in the clinical work for partial fulfillment of the graduation requirements. The author would like also to thank all participants for their cooperation.

\section{REFERENCES}

1. Demircia M., Tuncera S., Yuceokurb A. A. Prevalence of caries on individual tooth surfaces and its distribution by age and gender in university clinic patients. European Journal of Dentistry. 2010;4:270-279.

2. Tinanoff N, Palmer C. Dietary determinants of dental caries and dietary recommendation for preschool children. J. Public Health Dent.2000;60: 197-206.

3. Moynihan P. The interrelationship between diet and oral health. Proceedings of the Nutrition Society. 2005;64(4):571-580.

4. Nielsen S. J., Popkin B. M. Changes in beverage intake between 1977 and 2001. American Journal of Preventive Medicine. 2004; 27(3):205-210. 
5. Gupta P, Gupta n, Pawar A, Biraidar S, Natt A, Singh H. Role of Sugar and Sugar Substitutes in Dental Caries: A Review. ISRN Dentistry.2013; 1-5.

6. Azrak B, Willershausen B, Meyer N, Callaway A. Course of changes in salivary $\mathrm{pH}$-values after intake of different beverages in young children. Oral Health Prev Dent. 2008;6(2):159-64.

7. Leone C, Oppenheim F. Physical and chemical aspects of saliva as indicators of risk for dental caries in humans. J. Dent. Educ. 2001; 65:1054-1062.

8. Watt R. Strategies and approaches in oral disease prevention and health promotion. Bull. World Health Organ. 2005; 83:711-718

9. Bellini H, Arneberg P, von der Fehr. Oral hygiene and caries. A review. Acta Odontol Scand.1981, 39:257-265.

10. Mirjalili N, Karbassi MHA, Farahman J comparing tap water mouth rinse with tooth brushing and sugar free chewing gum: investigating the validity of a popular belief. J Dent Oral Hyg .2014; 6: 22-25.

11. Panchal V, Gurunathan D. . Comparison of Salivary PH Changes with Tap Water and Mineral Water Rinse after 50\% Sucrose Solution Rinse: A Cross-Over Trial. J Clin Diagn Res. 2017; 5:1-5.

12. Hans R, Thomas S, Garla B, Dagli R, Hans M. Effect of Various Sugary Beverages on Salivary pH, Flow Rate, and Oral Clearance Rate amongst Adults. Hindawi Publishing Corporation Scientifica. 2016 : 1-6.

13. Pachori A, Kamballimath H, Maran S, Niranjan B, Bhambhani G, Malhotra G. Evaluation of changes in salivary $\mathrm{pH}$ after intake of different eatables and beverages of children at different time intervals.Int J Clin Pediatr Dent. 2018; 11(3):177-182.
14. Mahajan N, Kotwal B, Sachdev V, Rewal N, Gupta R, Goyal S. Effect of commonly consumed sugar containing and sugar free fruit drinks on the hydrogen ion modulation of human dental plaque. Journal of Indian Society of Pedodontics and Preventive Dentistry 2014; 32:26-32

15. Nagler R, Hershkovich O. Age related changes in unstimulated salivary function and comparison and its relation to medications and oral sensorial complaints. Aging Clinical and Experimental Research. 2005; 17: 358-366.

16. Mohammadi S, Parashant G, Kumar P, Imranulla M, Rai R. Effect of different sugar free flavored chewing gums on salivary $\mathrm{pH}$ - a double blinded, parallel arm randomized clinical trial. British Journal of Medicine and Medical Research .2016; 13:1-6.

17. Francois Roulet, Massimo Fuzzi. Advances in Operative Dentistry, 2001; ðp 61-73.

18. Dehghan M, Tantbirojn D, Kymer-Davis E, Stewart CW, Zhang YH. Nutralizing salivary $\mathrm{pH}$ by mouthwashes after an acidic challenge. J Investigative and Clinical Dentistry 2017; 8:1-5.

19. Uma E, Kan ST, Lim LHY, Low HY, Varghese E, Soe HHK. Comparison of salivary $\mathrm{pH}$ changes after consumption of two sweetened Malaysian local drinks among individuals with low caries experience: a pilot study. Malays J Med Sci. 2018;25(4):100-111

20. Azrak B, Callaway A, Knözinger S, Willershausen B. Reduction of the $\mathrm{pH}$-values of whole saliva after the intake of apple juice containing beverages in children and adults. Oral Health and Preventive Dentistry 2003; 3:229-236.

21. Kulthanan K, Nuchkull P, Varothai S . The $\mathrm{pH}$ of water from various sources : an overview for recommendation for patients with atopic dermatitis. Asia Pac Allergy 2013; 3:155-160. 